\title{
ANATOMIA DA MADEIRA DE ASPIDOSPERMA RIEDELII MÜLL. ARG. (APOCYNACEAE) ${ }^{1}$
}

\author{
DIONE DAMBRÓS RADDATZ ${ }^{2}$ PAULO FERNANDO DOS SANTOS MACHADO ${ }^{3}$ \\ ROSSANA CORTELINI DA ROSA ${ }^{4}$ RITA DOS SANTOS SOUSA ${ }^{5}$ \\ FABRÍCIO JAQUES SUTILI ${ }^{6}$ JOSÉ NEWTON CARDOSO MARCHIORI $^{7}$
}

\begin{abstract}
RESUMO
O lenho de Aspidosperma riedelii é anatomicamente descrito e ilustrado com fotomicrografias. Na estrutura anatômica destacam-se: porosidade difusa; vasos solitários; poros de diâmetro muito pequeno e com paredes finas; parênquima apotraqueal; raios estreitos, em sua maioria unisseriados; e fibras pouco lignificadas. Com exceção dos dois primeiros caracteres, que têm ampla ocorrência no gênero em estudo, os demais agregam flexibilidade a ramos e caules e, sendo comuns em reófitas, confirmam a espécie como promissora para utilização em obras de engenharia natural e recuperação de áreas degradadas, em margens de cursos de água. Palavras-chave: anatomia da madeira; Apocynaceae; Aspidosperma riedelii; reófitas; restauração ecológica.
\end{abstract}

\section{ABSTRACT}

[Anatomy of the wood of Aspidosperma riedelii Müll. Arg. (Apocynaceae)].

The wood of Aspidosperma riedelii is anatomically described and illustrated with photomicrographs. The following features stand out in the wood structure: diffuse porosity; solitary vessels; very small pores, with thin walls; apotracheal parenchyma; narrow rays, mostly uniseriate; and weakly lignified fibers. With exception of the two first anatomical features, which are of wide occurrence in the genus under study, the others add flexibility to branches and stems and, being common in reophytes, confirm the species as promising for use in soil bioengeneering works and restoration of degraded areas along waterways.

Key words: Apocynaceae; Aspidosperma riedelii; reophytes; ecological restoration; Wood Anatomy.

1 Recebido em 10-III-2018 e aceito para publicação em $15-\mathrm{V}-2018$.

2 Engenheiro Florestal, mestrando do Programa de PósGraduação em Engenharia Florestal, Universidade Federal de Santa Maria. Santa Maria, RS, Brasil. dionedambros@hotmail.com

3 Engenheiro Florestal, doutorando do Programa de PósGraduação em Engenharia Florestal, Universidade Federal de Santa Maria. Santa Maria, RS, Brasil. barcasole@gmail.com

4 Engenheira Florestal, mestranda do Programa de PósGraduação em Engenharia Florestal, Universidade Federal de Santa Maria. Santa Maria, RS, Brasil. ro.cortelini@hotmail.com

5 Engenheira Biofísica, doutoranda do Programa de PósGraduação em Engenharia Florestal, Universidade Federal de Santa Maria. Santa Maria, RS, Brasil. ritasousa.ufsm@gmail.com

6 Engenheiro Florestal, Dr., Professor Adjunto do Departamento de Ciências Florestais, Universidade Federal de Santa Maria. Santa Maria, RS, Brasil. Fjsutili@gmail.com

7 Engenheiro Florestal, Dr., Professor Titular do Departamento de Ciências Florestais, Universidade Federal de Santa Maria. Santa Maria, RS, Brasil. marchioricfl@gmail.com

\section{INTRODUÇÃO}

As plantas reófilas pertencem a um grupo de vegetação típico da margem e leito de rios, córregos, ilhas fluviais e corredeiras, que se desenvolve em áreas passíveis de inundação e resiste à força da correnteza por ocasião de enchentes, resultantes de elevadas precipitações em áreas situadas à montante (Van Steenis, 1981). No Sul do Brasil, as reófitas distribuemse em 21 famílias, salientando-se Euphorbiaceae, Fabaceae e Myrtaceae (Arioli et al., 2008).

Além de abrigo e fonte de alimento para a ictiofauna, as plantas reófilas são importantes para a estabilização e proteção de taludes fluviais. No Brasil, com o desenvolvimento da Engenharia Natural, estas espécies passaram a servir como material construtivo vivo, em obras de estabilização hidráulica (Sousa \& Sutili, 2017); a estrutura anatômica, nesta circunstância, contribui para a compreensão do compor- 
tamento técnico da madeira face à velocidade do fluxo de água (Siegloch et al., 2011a).

O presente trabalho visa a descrever e ilustrar com fotomicrografias os caracteres anatômicos do lenho de Aspidosperma riedelii, comparar a estrutura com a de espécies afins, constantes na literatura, bem como analisar a mesma sob o ponto de vista da reofilia.

\section{REVISÃO DE LITERATURA}

Com cerca de 370 gêneros, 5.000 espécies e distribuição cosmopolita (Endress, 2004; Matozinhos \& Konno, 2011; Nazar et al., 2013), a família Apocynaceae é uma das dez mais numerosas de Angiospermas (Rapini, 2012), registrando-se, no Brasil, cerca de 70 gêneros e 750 espécies, distribuídas em diferentes domínios morfoclimáticos (Souza \& Lorenzi, 2012).

Diversas Apocináceas exóticas são cultivadas como ornamentais no país, salientando-se Thevethia peruviana (chapéu-de-Napoleão), Catharanthus roseus (vinca, pervinca), Nerium oleander (espirradeira) e o gênero Allamanda L., este com diversas espécies. A família também se destaca no fornecimento substâncias medicinais, casos da Leucocristina e Vincristina, utilizadas no tratamento do câncer e extraídas de Catharanthus roseus, bem como glicosídeos e alcalóides importantes para a química fina.

Presente em diferentes formações florestais, o gênero Aspidosperma Mart. \& Zucc. destacase por sua importância medicinal e econômica (Pereira et al., 2016), salientando-se, por suas madeiras no Sul do Brasil, o guatambu (Aspidosperma australe), o guatambu-mirim (Aspidosperma olivaceum) e o quebracho-branco (Aspidosperma quebrachoblanco), integrantes das flora sul-rio-grandense (Sobral \& Jarenkow, 2013), bem como a peroba-poca (Aspidosperma cylindrocarpon), nativa no Cerrado, e a peroba-rosa (Aspidosperma polyneuron), abundante na Floresta Estacional da bacia do Rio Paraná (Souza \& Lorenzi, 2012).

Objeto do presente estudo, Aspidosperma riedelii Müll. Arg. difere das espécies precedentes por ser arvoreta ou arbusto de até $5 \mathrm{~m}$ de altura e por sua ocorrência em ambiente reófilo. Embora rara na natureza, a espécie apresenta ampla distribuição geográfica, havendo registros em herbário desde o Nordeste (Piauí, Ceará, Paraíba, Bahia) ao Sul do país, incluindo o Rio de Janeiro, São Paulo e, até mesmo, o estado de Goiás. Kinoshita et al. (2005) atribuem à espécie uma distribuição disjunta, no Brasil e Paraguai, referindo a preferência dos indivíduos por "terrenos pedregosos" e a proximidade de "cursos de água". Não custa lembrar que o lectótipo da espécie foi coletado por Riedel (s.n.) no "Salto do rio Itu", interior do estado de São Paulo.

Entre os caracteres botânicos da espécie, Kinoshita et al. (2005) incluem: folhas congestas no ápice de ramos, espatuladas ou obovadas, cartáceas, curto-pecioladas $(0,2-0,3 \mathrm{~mm})$, de ápice arredondado e base aguda ou cuneada, decurrente no pecíolo; inflorescência subapical, fasciculada, séssil ou com pedicelo de $2-5 \mathrm{~mm}$ (Figura 1E); cálice de 3mm, com lacínias geralmente iguais, agudas ou oblongas; corola com tubo de 2,5-3mm, brancacento, glabro, inflado na região dos estames e com lobos acuminadoreflexos; estames inseridos no quarto superior do tubo; ovário com parte superior pilosa ou glabra; folículo piriforme $(3 \times 1,5 \mathrm{~cm})$, estipitado e mucronado (Figura 1F), de costa um pouco excêntrica; e sementes ovais, de asa quase concêntrica.

Em recente estudo sobre biotécnica e formas de propagação da espécie, desenvolvido no Laboratório de Engenharia Natural (LaBEN) da Universidade Federal de Santa Maria, Aspidosperma riedelii mostrou resultados promissores em propagação vegetativa, com sobrevivência superior a 70\%, índice considerado "satisfatório" por autores como Sauli, Cornelini \& Pretti (2003) e Schiechtl (1973).

No tocante à anatomia do lenho, Metcalfe \& Chalk (1972) e Record \& Hess (1943) referem para o gênero Aspidosperma os seguintes caracteres: poros de diâmetro pequeno $(<100$ $\mu \mathrm{m})$ a médio (100-200 $\mu \mathrm{m})$, exclusivamente solitários; placas de perfuração simples, peque- 
nas em relação ao diâmetro dos vasos; pontoações intervasculares muito pequenas a diminutas, ornamentadas; pontoações para com os parênquimas axial e radial, similares; parênquima apotraqueal difuso ou em curtos segmentos unisseriados, raramente em contato com vasos; raios heterogêneos, com 4-10 fileiras de células quadradas e eretas nas margens, ou quase homogêneos; e fibras com pontoações areoladas e paredes espessas.

Para Aspidosperma australe, Muñiz \& Marchiori (1998), Mattos et al. (2003) e Marchiori et al. (2010) referem: vasos arredondados (40-65-76 $\mu \mathrm{m})$, em sua maioria solitários, com raros geminados ou grupos de 3 ; poros em número de $50-64-80 / \mathrm{mm}^{2}$; elementos vasculares de 280-505-700 $\mu \mathrm{m}$ de comprimento; raios homogêneos, com 2-15 células de altura e em número de $8-10 / \mathrm{mm}$, unisseriados ou bisseriados-em-parte; e fibras de paredes espessas, de 740-1160-1340 $\mu$ m de comprimento, com pontoações distintamente areoladas.

Espécie chaquenha e de ocorrência restrita, no Rio Grande do Sul, a solos salinos (blanqueales) do Parque Estadual do Espinilho (Marchiori et al., 2014), Aspidosperma quebracho-blanco conta, pelo menos, com três descrições anatômicas da madeira, realizadas por Tortorelli (1956), Marchiori (1985) e Marchiori et al. (2009). Além dos caracteres apontados por Metcalfe \& Chalk (1972), a estrutura da madeira apresenta: poros arredondados (27-57-93 $\mu \mathrm{m})$, em número de 17-29$46 / \mathrm{mm}^{2}$ e tipicamente solitários, com raros geminados; elementos vasculares de 207-360$525 \mu \mathrm{m}$ de comprimento; raios com 1-3-6 células de largura, em número de 8-10-14/mm; e fibras muito curtas a curtas (735-1125-1362 $\mu \mathrm{m})$, de paredes espessas e fortemente lignificadas.

Importante espécie madeireira na bacia do rio Paraná, Aspidosperma polyneuron apresenta, segundo Tortorelli (1956): poros de 40-80120 um de diâmetro, em número de $45-65 / \mathrm{mm}^{2}$; elementos vasculares curtos a medianos (150430-500 $\mu \mathrm{m}$ ); raios em número de 8-11/mm, em sua maioria bisseriados (raros unisseriados); e fibras curtas a medianas (700-1000-1250 $\mu \mathrm{m}$ ), de paredes espessas.

Na literatura anatômica brasileira salientamse, ainda, outros dois estudos sobre madeiras de Aspidosperma, procedentes da Caatinga (Paula \& Alves, 1980) e do estado do Pará (Reis, 2015), respectivamente.

\section{MATERIAL E MÉTODOS}

A amostra de madeira para estudo anatômico foi coletada no vale do Rio das Antas (Rio Grande do Sul), nas proximidades da ponte da RS 448, que liga os municípios de Farroupilha e Nova Roma do Sul. O material botânico correspondente foi incorporado aos Herbários SMDB (Departamento de Biologia Santa Maria) e HDCF (Herbário Departamento de Ciências Florestais), com os números 17.530 e 7.522 , respectivamente.

Do material lenhoso foram extraídos três corpos-de-prova $(3 \times 3 \times 3 \mathrm{~cm})$, orientados para a obtenção de cortes anatômicos nos planos transversal, longitudinal radial e longitudinal tangencial, além de um fragmento destinado à maceração.

Os corpos-de-prova foram fervidos em água, por cerca de 60 horas e, na sequência, seccionados em micrótomo de deslize (modelo Leica), no Laboratório de Anatomia da Madeira da Universidade Federal de Santa Maria (UFSM).

A confecção das lâminas de cortes anatômicos seguiu a metodologia descrita por Burger \& Richter (1991), usando-se coloração com Safrablau, desidratação em série alcoólica crescente e montagem permanente, com Entellan.

No preparo de lâminas de macerado, finos palitos de madeira foram obtidos por lascamento e fervidos em tubo de ensaio, com água, por duas horas. Na maceração propriamente dita, seguiuse o método de Jeffrey (Freund, 1970). Usou-se coloração da pasta de fibras com Safranina e, na montagem das lâminas, a mesma resina anteriormente citada. 

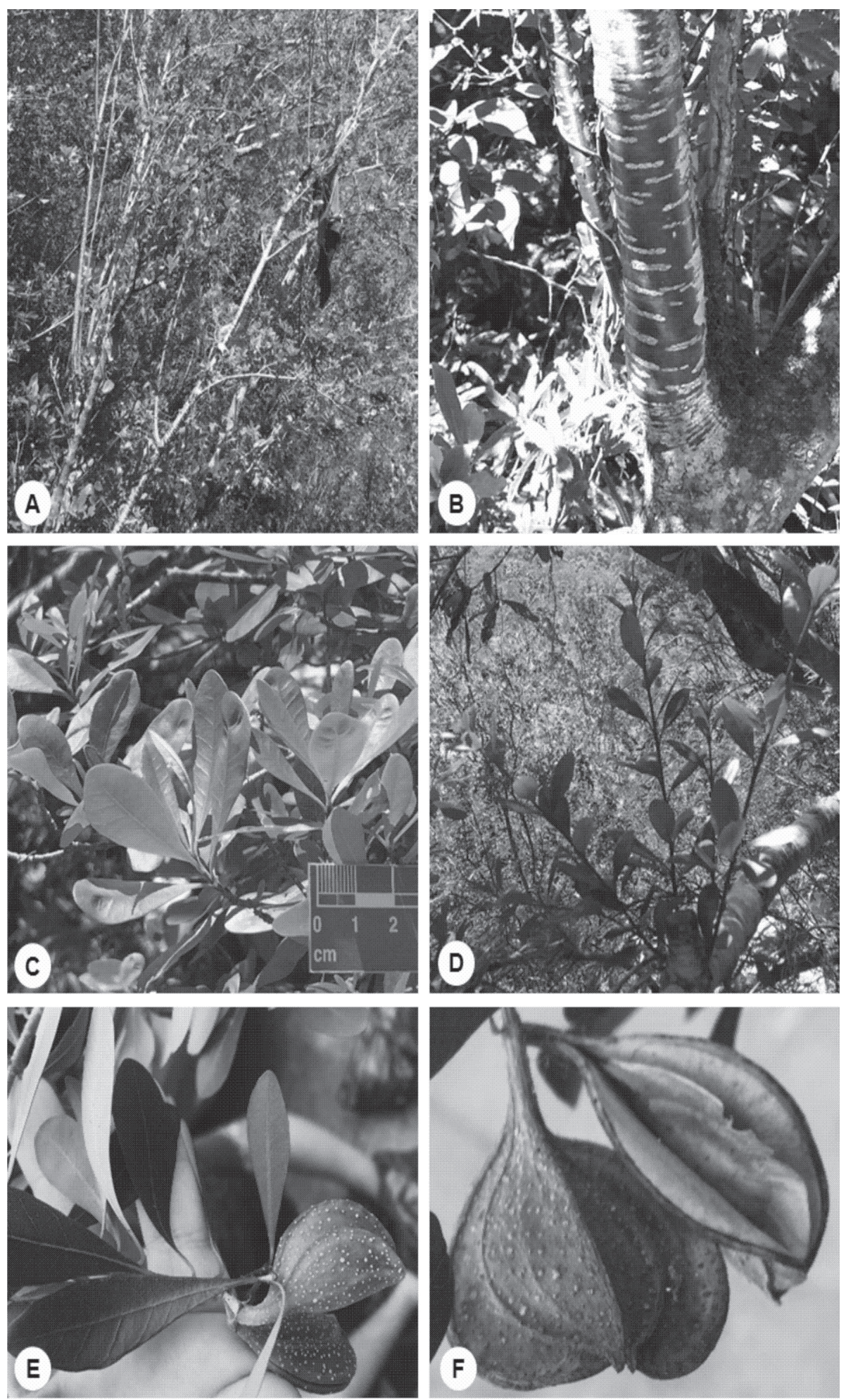

FIGURA 1: Aspidosperma riedelii A - Aspecto geral de um indivíduo. B - Detalhe do caule. C, D-Detalhe das folhas. E - Frutos verdes. F - Frutos maduros. 
A descrição do lenho seguiu as recomendações do IAWA Committee (Wheeler et al., 1989). A percentagem ocupada pelos distintos tecidos constituintes da madeira foi definida em plano transversal e com o uso de um contador de laboratório, mediante 600 determinações ao acaso, conforme Marchiori (1980). A frequência de poros foi obtida a partir de um quadrado de área conhecida, superposto a fotomicrografias em diferentes pontos de secções transversais. Os demais caracteres anatômicos foram medidos em microscópio binocular Carl Zeiss, provido de escala graduada.

As imagens que ilustram o texto foram tomadas em fotomicroscópio Leica, modelo DM 2000, munido com câmera digital Leica (modelo DFC 295), no Laboratório de Botânica Estrutural do Departamento de Biologia da UFSM.

$\mathrm{Na}$ citação das características quantitativas, os números entre parênteses correspondem aos valores mínimos e máximos observados; o valor que acompanha a média é o desvio padrão.

\section{DESCRIÇÃO DA MADEIRA}

Anéis de crescimento: distintos, marcados pela maior abundância de parênquima axial e poros no lenho inicial.

Vasos: numerosos $\left(35 \pm 6(28-49) / \mathrm{mm}^{2}\right)$, solitários, menos comumente geminados, compondo $21 \pm 6 \%$ do volume da madeira. Poros mais abundantes no lenho inicial, configurando padrão semidifuso (Figura 2A, B). Poros de (24 $\pm 5(13-33) \mu \mathrm{m})$ de diâmetro, poligonais e de paredes finas $(2,5 \pm 0,1(1,9-2,5) \mu \mathrm{m})$ (Figura $2 \mathrm{~A}, \mathrm{~B})$. Elementos vasculares de comprimento médio $(488 \pm 94(310-670) \mu \mathrm{m})$, com placas de perfuração simples, oblíquas, e apêndices curtos a longos $(61 \pm 41(10-200) \mu \mathrm{m})$, geralmente em ambas as extremidades. Pontoações intervasculares de difícil visualização, pelo raro contato entre poros; pequenas e arredondadas $(3,8 \pm 0,5(3,1-4,6) \mu \mathrm{m})$, ornamentadas e em arranjo alterno. Pontoações raio-vasculares, semelhantes às intervasculares $(2,7 \pm 0,5(2,1-$ $3,1) \mu \mathrm{m})$; pontoações parênquimo-vasculares de difícil visualização, pelo escasso contato entre as células envolvidas.

Parênquima axial: representando $5 \pm 1 \%$ do volume da madeira; apotraqueal difuso-em-agregados, ao longo do anel; mais abundante no início dos anéis de crescimento (Figura 2A, B). Séries parenquimáticas de $398 \pm 81(263-550)$ $\mu \mathrm{m}$ de altura, com $2-6$ células (Figura 2F). Cristais romboédricos, em séries; cristais visíveis, inclusive, em seção transversal.

Raios: muito numerosos $(20 \pm 2,3(16-23)$ raios/mm), ocupando $15 \pm 5 \%$ do volume da madeira; estreitos $(15 \pm 4(13-28) \mu \mathrm{m})$ e homogêneos, compostos de células procumbentes (Figura 2C, D). Os unisseriados, predominantes $(93 \%)$, de $145 \pm 63(40-275) \mu \mathrm{m}$ e $4-23$ células de altura; raios bisseriados, raros (3\%). Células radiais de contorno arredondado, em plano tangencial (Figura 2E, F); células envolventes, células radiais de paredes disjuntas e células perfuradas, ausentes. Raios fusionados e conteúdos, presentes.

Fibras: de comprimento médio $(922 \pm 118$ $(700-1100) \mu \mathrm{m})$, com $14 \pm 1,9(8-18) \mu \mathrm{m}$ de largura e paredes espessas $(3,7 \pm 0,7(2,5-5)$ $\mu \mathrm{m})$, pouco lignificadas, ocupando $59 \pm 4 \%$ do volume da madeira (Figura 2A, B); pontoações, simples ou com aréolas muito pequenas. Espessamentos espiralados, fibras septadas e traqueídeos, ausentes.

Outros caracteres: variantes cambiais, tubos laticíferos e taniníferos, canais intercelulares, células oleíferas, células mucilaginosas, estratificação e máculas medulares, ausentes.

\section{DISCUSSÃO}

A estrutura anatômica da madeira de Aspidosperma riedelii corresponde, em linhas gerais, ao relacionado por Metcalfe \& Chalk (1972) e Record \& Hess (1943) para o gênero Aspidosperma: poros geralmente solitários; placas de perfuração exclusivamente simples; espessamentos espiralados e canais intercelulares, ausentes; pontoações ornamentadas, pequenas ou muito pequenas; parênquima axial 

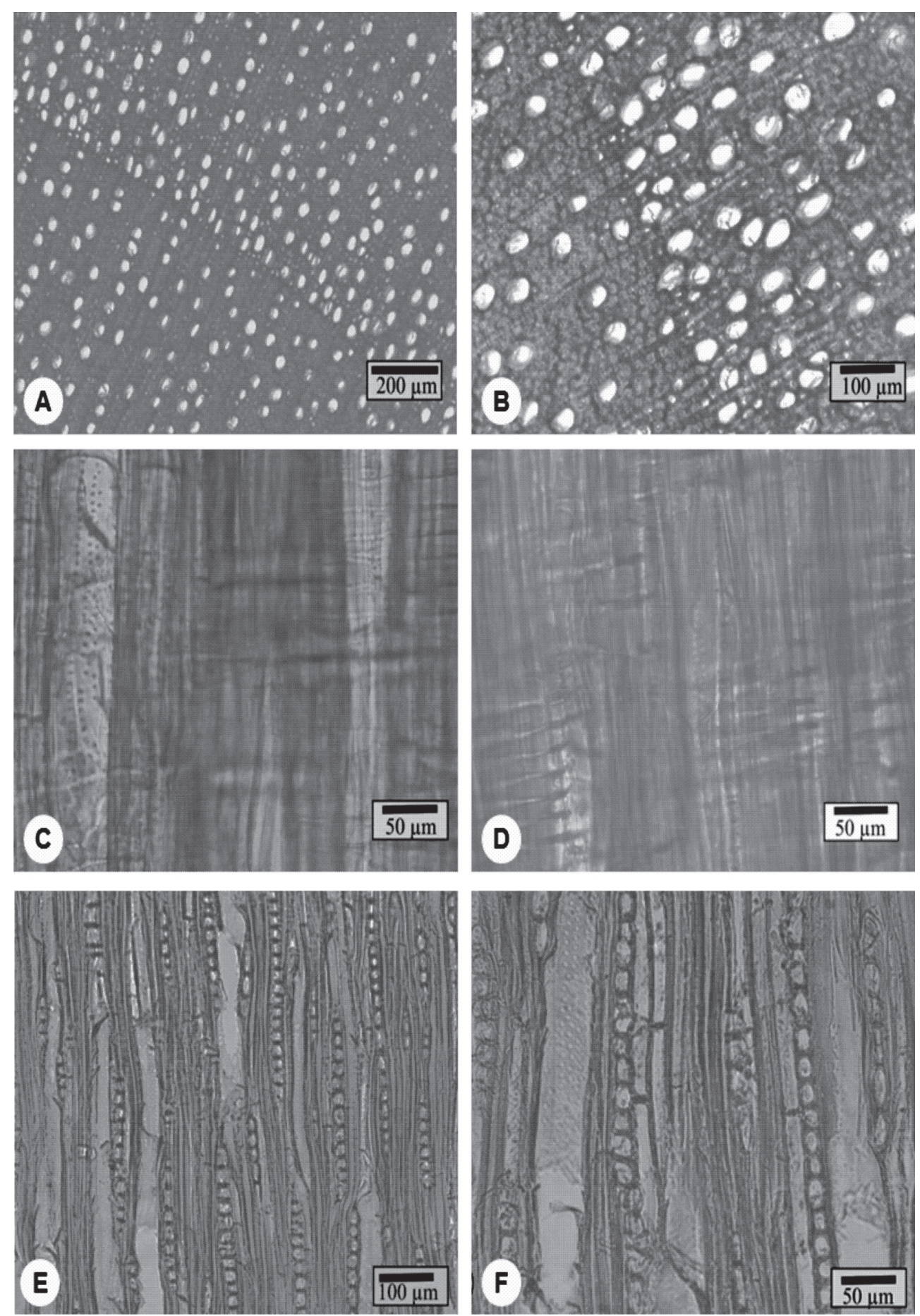

FIGURA 2: Aspectos anatômicos do lenho de Aspidosperma riedelii. A - Anéis de crescimento distintos, porosidade semidifusa e poros extremamente numerosos, solitários, mais abundantes no lenho inicial. B - Poros solitários, mais abundantes no lenho inicial, fibras de paredes espessas e parêquima axial difuso em-agregados. C, D - Raios homogêneos, compostos, inteiramente, de células procumbentes. E, F - Raios unisseriados, pontoações parênquimo-vasculares, fibras de paredes espessas e parênquima axial seriado. 
apotraqueal; raios estreitos, homogêneos (ou quase); e fibras de pontoações areoladas (fibrotraqueóides). Cabe salientar que Aspidosperma riedelii insere-se no grupo das espécies que apresentam raios homogêneos (com células procumbentes), posto que em outras, do mesmo gênero, observam-se raios nitidamente heterogêneos.

A abundância de poros, bem como o comprimento de fibras e de elementos vasculares observados em Aspidosperma riedelii aproximam-se dos valores citados por Marchiori (1985), Marchiori et al. (2009, 2010), Mattos et al. (2003), Muñiz \& Marchiori (1998) e Tortorelli (1956), para A. australe, A. polyneuron e A. quebrachoblanco.

$\mathrm{Na}$ comparação anatômica da madeira de Aspidosperma riedelii com as espécies investigadas por Marchiori (1985), Marchiori et al. (2009, 2010), Mattos et al. (2003), Muñiz \& Marchiori (1998) e Tortorelli (1956), chama atenção que a espécie em estudo é a que apresenta vasos de menor diâmetro médio $(24 \mu \mathrm{m})$, valor inferior à metade do observado em $A$. quebrachoblanco $(57 \mu \mathrm{m})$, espécie sabidamente xerófila e de solos salinos, e ainda mais contrastante com o verificado em A. australe (64 $\mu \mathrm{m})$ e A. polyneuron ( $80 \mu \mathrm{m})$, que são espécies da Floresta Estacional sul-brasileira. Em anatomia ecológica, é bem sabido que vasos de pequeno diâmetro é caráter associado à xeromorfia, motivo pelo qual predomina em espécies de desertos, semidesertos, bem como em epífitas e plantas lenhosas de solos salinos ou manguezais (Carlquist, 1980; Baas, 1985; Melo Júnior, 2016).

Vasos de pequeno diâmetro, todavia, também estão associados à "síndrome anatômica de reofilia”, definida, por Denardi (2007) com base no estudo de Phyllanthus sellowianus, que apresenta vasos com diâmetro médio de $29 \mu \mathrm{m}$, Sebastiania schottiana $(48 \mu \mathrm{m})$, Salix x rubens $(57 \mu \mathrm{m})$ e Salix humboldtiana $(64 \mu \mathrm{m})$. No presente trabalho, a ocorrência de poros de diâmetro ainda menor em Aspidosperma riedelii do que na xerófila A. quebrachoblanco se explica, unicamente, como mecanismo anatômicoadaptativo de reofilia. Poros igualmente muito pequenos foram observados em outras espécies sabidamente reófilas, como Colliguaya brasiliensis (Siegloch et al., 2011a), Ruprechtia salicifolia (Santos et al., 2011), Cephalanthus glabrathus (Siegloch et al., 2011b) e Callisthene inundata (Siegloch et al., 2011c).

A associação entre poros de pequeno diâmetro e reofilia deve-se ao ganho em flexibilidade proporcionado pelos mesmos e, por conseguinte, ao menor risco de ruptura da madeira ao ser submetida ao referido esforço, uma vez que os vasos, por seu diâmetro, geram linhas de fraqueza. No ambiente reófilo, todavia, ao contrário do verificado em xerófitas, os vasos podem ter paredes finas, caso de Aspidosperma riedelianum, Colliguaya brasiliensis, Callisthene inundata e outras espécies ecologicamente afins.

Outro aspecto anatômico de vasos vinculado à "síndrome anatômica de reofilia" é a ocorrência de poros solitários (Denardi, 2007). Este caráter, entretanto, não pode ser aventado no caso da espécie em estudo, visto sua ampla ocorrência no gênero Aspidosperma.

A respeito do parênquima axial, tecido composto de células com paredes relativamente finas e pouco lignificadas, aspectos que, em princípio, parecem favoráveis à flexibilidade, Denardi (2007) postulou a associação de reofilia com padrões apotraqueais e, até mesmo, com a ausência desse tecido. De fato: faixas largas de parênquima axial representam linhas de fraqueza, propiciando a ocorrência de linhas de ruptura em madeiras submetidas a esforços. Desse modo, a escassa abundância e o arranjo apotraqueal, observados no lenho de Aspidosperma riedelii, também depõem, favoravelmente, ao caráter reófilo da espécie.

Com relação à largura de raios, caráter igualmente arrolado na "síndrome anatômica de reofilia" (Denardi, 2007), a expressiva predominância de unisseriados (raros bisseriados) em Aspidosperma riedelii também reforça a hipótese da inclusão da espécie no contingente 
reófilo, apesar do mesmo ser igualmente observado em A. australe (Muñiz \& Marchiori, 1998; Marchiori et al., 2010), espécie não reófila e da Floresta Estacional. Na peroba-rosa ( $A$. polyneuron) predominam os bisseriados (Tortorelli, 1956) e os trisseriados em $A$. quebrachoblanco, espécie em que se observam raios com até 6 células de largura (Marchiori, 1985; Marchiori et al., 2009).

Cumpre salientar que na madeira de Aspidosperma riedelii, ao contrário do observado nas espécies reófilas anteriormente referidas, não se observaram fibras verdadeiramente gelatinosas. Caráter bem conhecido por conferir flexibilidade a ramos e caules inclinados, até mesmo por sua invariável presença no lenho de tensão (Jane, 1962; Panhin \& De Zeeuw, 1970; Tsoumis, 1969), o que verdadeiramente ocorre no lenho presentemente descrito é uma baixa lignificação do tecido fibroso, demonstrada pela escassa fixação do corante Safranina nas lâminas de cortes anatômicos, as quais apresentam tom rosado-claro.

O pequeno porte dos indivíduos de Aspidosperma riedelii e o correspondente pequeno diâmetro de seus troncos também cabem ser ressaltados - mas, neste caso, como aspectos dendrológicos -, em favor da inclusão da espécie no contingente reófilo da flora sul-brasileira.

\section{CONCLUSÃO}

O estudo microscópico da madeira de Aspidosperma riedelii (Apocynaceae) demonstra o caráter reófilo da espécie, com base na ocorrência de vasos solitários, de pequeno diâmetro e paredes finas, no parênquima apotraqueal (e pouco abundante), nos raios unisseriados, e na escassa lignificação da parede de fibras.

\section{REFERÊNCIAS BIBLIOGRÁFICAS}

ARIOLI, T.; VOLTOLINI, C.H.; SANTOS, M. Leaf morphoanatomy of the rheophyte Raulinoa echinata R.S. Cowan, Rutaceae. Acta Botanica Brasilica, v. 22, n. 3, p. 723-7632, 2008.
BAAS, P. Some functional and adaptative aspects of vessel member morphology. Leiden Botanical Series, v. 3, p. 157-181, 1985.

BURGER , L.M.; RICHTER, H.G. Anatomia da Madeira. São Paulo: Ed. Nobel, 1991. 154 p.

CARLQUIST, S. Further concepts in ecological wood anatomy, with comments on recent work in wood anatomy and evolution. Aliso, v. 9, n. 4, p. 499$553,1980$.

DENARDI, L. Anatomia e flexibilidade do caule de quatro espécies lenhosas para o manejo biotécnico de cursos de água. Tese (Doutorado em Engenharia Florestal). Santa Maria: Univ. Federal de Santa Maria, 2007. 112 f.

ENDRESS, M.E. Apocynaceae: brown and now. Telopea, n. 10, p. 525-541, 2004.

FREUND, H. Handbuch der Mikroskopie in der Technik. Frankfurt: Umsham Verlag, 1970. 375 p.

JANE, F.W. The structure of Wood. London: Adam \&Charles Black, 1962. $427 \mathrm{p}$.

KINOSHITA, L.S.; SIMÕES, A.O; KOCH, I.; SALES, M.F. de; RIO, M.C.S.; MARCONDES-FERREIRA, W. Apocynaceae. In: WANDERLEY, M. das G.L.; SHE-PHERD, G.G.; MELHEM, T.S.; GIULIETTI, A.M. Flora Fanerogâmica do Estado de São Paulo. São Paulo: FAPESP: RiMa, 2005. p. 35-91.

MARCHIORI, J.N.C. Estudo anatômico do xilema secundário de algumas espécies dos gêneros Acacia e Mimosa, nativas no estado do Rio Grande do Sul. 1980. 186 f. Dissertação (Mestrado em Engenharia Florestal) Universidade Federal do Paraná, Curitiba, 1980.

MARCHIORI, J.N.C. Anatomia descritiva da madeira de quebracho-branco (Aspidosperma quebrachoblanco Schlecht.). Ciência \& Natura, Santa Maria, n. 7, p. 99-106, 1985.

MARCHIORI, J.N.C.; ALVES, F. da S.; DEBLE, L.P.; OLIVEIRA-DEBLE, A.S. de. A vegetação no Parque Estadual do Espinilho. 2 - Origem do nome e considerações fitogeográficas. Balduinia, Santa Maria, n. 44, p. 1-16, 2014.

MARCHIORI, J.N.C.; MUÑIZ, G.I.B. de; SANTOS, S.R. dos. Madeiras do Rio Grande do Sul. 1 Descrição microscópica de 33 espécies nativas. Santa Maria: [s.n.], 2009. 80 p.

MARCHIORI, J.N.C.; MUÑIZ, G.I.B. de; SANTOS, S.R. dos. Madeiras do Rio Grande do Sul. 2 Descrição microscópica de 35 espécies nativas. Santa Maria: Anaterra, 2010. 80 p. 
MATOZINHOS, C.N.; KONNO, T.U.P. Diversidade taxonômica de Apocynaceae na Serra Negra, MG, Brasil. Hoehnea, v. 38, n. 4, p. 569-595, 2011.

MATTOS, P.P. de; TEIXEIRA, L.L.; SEITZ, R.A.; SALIS, S.M. de; BOTOSSO, P.C. Anatomia de madeiras do Pantanal Mato-Grossense (Características microscópicas). Colombo: Empresa Brasileira de Pesquisa Agropecuária, 2003. 182 p.

MELO JÚNIOR, J.C.F. de; AMORIM, M.W.; ARRIOLA, I.A. Anatomia da madeira de Swartzia brasiliensis (Choisy) Bedell ex Gir.Cañas (Marcgraviaceae). Balduinia, Santa Maria, n. 55, p. 8-16, 2016.

METCALFE, C.R.; CHALK, L. Anatomy of the Dicotyledons. Oxford: Clarendon Press, 1972. $1500 \mathrm{p}$.

MUÑIZ, G.I.B. de; MARCHIORI, J.N.C. Anatomia da madeira de três Apocináceas da Floresta Estacional de Misiones, Argentina. Ciência \& Natura, Santa Maria, n. 20, p. 67-83, 1998.

NAZAR, N.; GOYDER, D.J.; CLARKSON, J.J.; MAHMOOD, T.; CHASE, M.W. The taxonomy and systematics of Apocynaceae. Bot. J. Linn. Soc., v.171, n. 3, p. 482-490, 2013.

PANSHIN, A.J.; DE ZEEUW, C. Textbook of Wood Technology. New York: Mc Graw-Hill, 1970. v. 1. $705 \mathrm{p}$.

PAULA, J.E.; ALVES, J.L.H. Estudo das estruturas anatômicas e de algumas propriedades físicas da madeira de 14 espécies ocorrentes em áreas de Caatinga. Brasil Florestal, n. 43, p. 47-58, 1980.

PEREIRA, A.S.S.; SIMÕES, A.O.; SANTOS, J.U.M. Taxonomy of Aspidosperma Mart. (Apocynaceae, Rauvolfioideae) in the State of Para, Northern Brazil. Biota Neotropica, v. 2, n. 16, 2016.

RAPINI, A. Taxonomy "under construction", advances in the systematics of Apocynaceae, with emphasis on the Brazilian Asclepiadoideae. Rodriguésia, v. 63, n. 1, p.75-88, 2012.

RECORD, S.J.; HESS, R.W. Timbers of the New World. New Haven: Yale Univ. Press, 1943. 640 p.

REIS, A.R.S. Anatomia da madeira de quatro espécies de Aspidosperma Mart. \& Zucc., comercializadas no estado do Pará, Brasil. Ciência da Madeira, v. 6, p. 47-62, 2015.
SANTOS, S.R. dos; SIEGLOCH, A.M.; MARCHIORI, J.N.C. Anatomia da madeira de Ruprechtia salicifolia (Cham. \& Schltdl.) C.A. Mey. Balduinia, Santa Maria, n. 28, p. 27-32, 2011.

SAULI, G.; CORNELINI, P.; PRETI, F. Manuale d' Ingegnaria Naturalistica applicabile ai settori delle strade, Cave, Discariche e Coste Sabbiose. Roma, Itália: Regione Lazio, 2003.

SCHIECHTL, H. Bioingegneria Forestale. basimateriali da construzioni vivi - metodi. Itália: Edizione Castaldi-Feltre, 1973.

SIEGLOCH, A.M.; SANTOS, S.R.; MARCHIORI, J.N.C. Estudo anatômico do lenho de Colliguaya brasiliensis Klotzsch ex Baill. (Euphorbiaceae). Balduinia, n. 27, p. 27-33, 2011a.

SIEGLOCH, A.M.; MARCHIORI, J.N.C.; SANTOS, S.R. Anatomia do lenho de Cephalanthus glabratus (Spreng.) K. Schum. (Rubiaceae). Balduinia, Santa Maria, n. 31, p. 20-26, 2011 b.

SIEGLOCH, A.M.; MARCHIORI, J.N.C.; SANTOS, S.R. Estudo anatômico do lenho de Callisthene inundata Bueno, Nilson \& Magalhães. Balduinia, Santa Maria, n. 32, p. 7-11, 2011c.

SOBRAL, M.; JARENKOW, J.A. (Eds.). Flora arbórea e arborescente do Rio Grande do Sul, Brasil. São Carlos: RiMa editora, 2013. 357 p.

SOUSA, R.S.; SUTILI, F.J. Aspectos Técnicos das Plantas utilizadas em Engenharia Natural. Ciência \& Ambiente, Santa Maria, n. 46/47, p. 31-71, 2017.

SOUZA, V.C.; LORENZI, H. Botânica sistemática. Nova Odessa: Instituto Plantarum, 2012.

TORTORELLI, L.A. Maderas y bosques argentinos. Buenos Aires: ACME, 1956. 910 p.

TSOUMIS, G. Wood as raw material. Oxford: Pergamon Press, 1969. 276 p.

VAN STEENIS, C.G.G.L. Rheophytes of the World. An account of the flood resistant flowering plants and ferns and the theory of autonomous evolution. Netherlands: Sijthoff \& Noordhopp, 1981.

WHEELER, E.A.; BAAS, P.; GASSON, P.E. IAWA list of microscopic features for Hardwood identification. IAWA Bulletin, v. 10, n. 3, p. 218359, 1989. 